McGraw-Hill, New York (1937).

24. Wenzel, L., and R. R. White, Ind. Eng. Chem., 43, 1829 (1951).

Manuscript received October 11, 1968; revision received February 26, 1969; paper accepted February 28, 1969.

\section{APPENDIX}

The thermocouple wires were likened unto two long rods whose terminal temperature was that of the drop and which exchanged heat with their surroundings by both radiation and convection. The wires were considered not to interfere with each other regarding this heat exchange. The usual assumptions of constant physical properties, a constant temperature environment, a constant heat transfer coefficient along the rod, no radial temperature profile in the rod, and a mathematically infinitely long rod, plus the additional assumptions of a geometry factor for radiation of unity and an emissivity factor equal to the emissivity of the wire, gave

$$
\frac{d^{2} T}{d z^{2}}+\frac{2}{R k_{t}}\left[\sigma \epsilon\left(T_{g}^{4}-T^{4}\right)+h_{t}\left(T_{g}-T\right)\right]=0
$$

for which the boundary conditions are at $z=0, T=T_{d}$, and at $z=\infty, T=T_{g}$ or at $z=\infty, d T / d z=0$. Integration gave

$$
\begin{aligned}
\frac{d T}{d z}= \pm & \left\{\frac { 2 } { R k _ { \mathrm { t } } } \left[\frac{2 \sigma \epsilon}{5}\left(T^{5}-T_{g}{ }^{5}\right)\right.\right. \\
& \left.\left.-2 \sigma \epsilon T_{g}^{4}\left(T-T_{g}\right)+h_{t}\left(T-T_{g}\right)^{2}\right]\right\}^{1 / 2}
\end{aligned}
$$

The rate at which heat was transferred to the drop by each wire followed from

$$
Q_{t}=-\left.\pi R^{2} k_{t} \frac{d T}{d z}\right|_{z=0}
$$

Evaluation of Equation (A3) with the aid of Equation (A2) yielded Equation (6).

\title{
Experimental Determinations of Several Thermal Properties of a Mixture Containing 51 Mole Percent Propane in Methane
}

\author{
V. F. Yesayage, D. L. KATZ, and J. E. POWERS \\ The University of Michigan, Ann Arbor, Michigan
}

Results of calorimetric determinations are reported for a mixture containing approximately 51 mole \% propane in methane. Measurements were made with both isobaric and throttling flow calorimeters in the liquid, critical, gaseous, and two-phase regions in the temperature range from $-250^{\circ}$ to $+300^{\circ} \mathrm{F}$. at pressures of between 100 and $2,000 \mathrm{lb} . / \mathrm{sq}$. in. abs. Tables of experimental values of heat copacity, Joule-Thomson coefficient, and isothermal throttling coefficient are presented, and the values of $C_{p}$ and $\phi$ are summarized on parametric plots.

Experimental values of enthalpy differences within the two-phase region determined under both isobaric and isothermal conditions are also reported together with the experimentally determined phose boundary dato. A skeleton enthalpy table is presented which is based almost entirely on experimental data obtained in this investigation. Comparisons are made with other published calorimetric data and with calculations based on PVT dato.

This article summarizes additional results in the continuing effort to obtain accurate experimental data on the thermal properties of light hydrocarbons, fixed gases, and their mixtures. It is anticipated that such data will serve to improve engineering design calculation not only by presenting accurate data but also by providing a firm basis for testing and extending methods of predicting the enthalpy of such materials.

All available literature data on methane, propane, and their mixtures have been summarized in previous publications $(17,1921,25,26,36)$. No additional calorimetric data have been noted since the last of the above reports (36) was presented.

\section{THERMODYNAMIC RELATIONS}

The basic equations for the interpretation of flow calorimetry data have been presented previously in a

\footnotetext{
V. F. Yesavage is at Shell Oil Company, Houston Research Laboratory, Deer Park, Texas.
}

number of references $(21,35,38)$. In brief, the first law of thermodynamics is applied to relate the change in specific enthalpy between inlet and outlet conditions to the measured rate of transfer of electrical energy $\dot{W}$ and the mass flow rate $F$. For the calorimeters used in the course of this investigation, kinetic and potential energy effects are insignificant, and the rate of heat leak $\dot{Q}$ is negligible.

$$
\left(\underline{H}_{T_{2}, P_{2}}-\underline{H}_{T_{1}, P_{1}}\right)_{x}=-\frac{\dot{W}}{F}
$$

In applying this equation to interpret results obtained in the isobaric flow calorimeter, the slight pressure drop through the calorimeter is taken into account. Similarly, the isothermal flow calorimeter is usually operated with a temperature difference of less than $0.05^{\circ} \mathrm{F}$., and this measured difference is accounted for in interpreting the results. Such corrections rarely amount to as much as $1 \%$. 


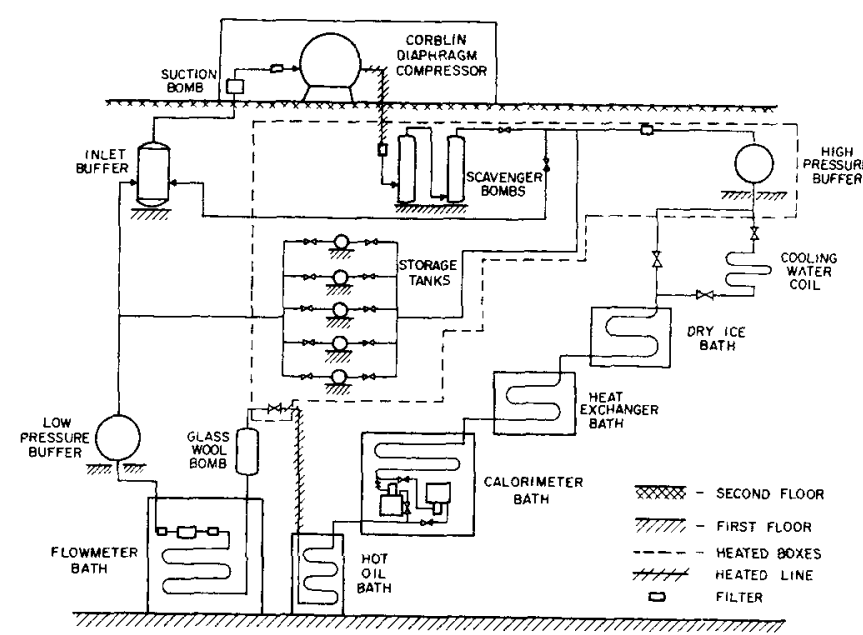

Fig. 1. Flow diagram of modified recycle system.

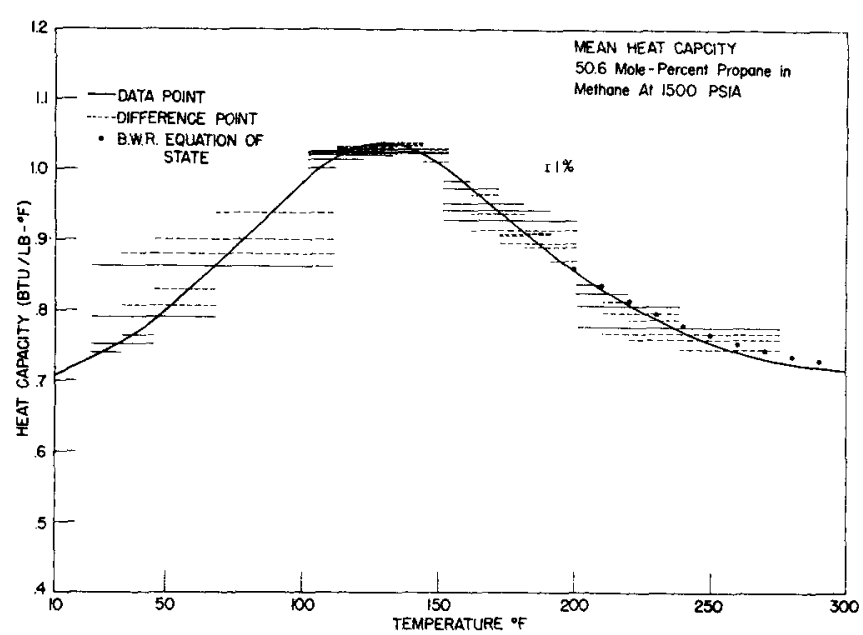

Fig. 3. Isobaric heat capacity at $1,500 \mathrm{lb} . / \mathrm{sq}$.in.abs. in the upper temperature range.

equation of state:

$$
\phi=\underline{V}-T\left(\frac{\partial \underline{V}}{\partial T}\right)_{P}
$$

\section{EXPERIMENTS}

\section{Equipment}

The recirculating system designed for operation at high pressures over an extended range of temperatures and mixture compositions has been described in detail in a previous report (24). A flow diagram of the revised facility is presented as Figure 1. As indicated, two flow calorimeters are incorporated in the facility. Modifications to the system have been described in a later report $(36)$. Since the time of the last report, copper filings have been added to the glass wool in one of the high pressure scavenger bombs in order to remove traces of oxygen from the system.

The isobaric calorimeter uses electrical energy to increase the enthalpy of the flowing fluid $(9,13)$. The throttling calorimeter makes use of a capillary tube with an insulated heating wire through its entire length to adjust the outlet temperature to that of the inlet $(19,20,22,23)$. Under conditions such that an isenthalpic decrease in pressure results in an increase in temperature, this throttling calorimeter is operated as a Joule-Thomson device (37).

\section{Procedure}

The operation of the calorimeter in the isobaric (13), isothermal (19), and isenthalpic (37) modes has been described in detail elsewhere. In carrying out this investigation, the electrical energy input to the calorimeters, $\dot{W}$, was determined by use of standard resistors and a K-3 potentiometer. The temperature at the inlet to the operating calorimeter is assumed to be equal to the temperature of the calorimeter bath which is determined by a platinum resistance thermometer. Duplicate six junction copper-constantan thermopiles were used in each calorimeter to determine temperature differences between the inlet and outlet. Both the thermometer and the thermopiles were calibrated by the National Bureau of Standards. The pressure at the inlet to the calorimeters is determined by use of a Mansfield and Green pressure balance. The slight pressure drop across the isobaric calorimeter is measured by means of a high pressure mercury manometer. The pressure drop across the throttling calorimeter is determined by using the differential pressure balance of Roebuck (30).

The rate at which the flowing gas passes through the calorimeter $F$ is perhaps the most critical measurement in the determination of enthalpy differences by the use of a flow calorimeter. A Meriam flowmeter was used and was calibrated by collecting samples over a measured time interval and determining the mass by weighing. Sets of approximately ten calibration runs are made with the mixture under study before

Fig. 2. Composition of system during time of investigation. 
Table 1. Composition of Nominal 51 Mole \% Propane in Methane Mixture as Determined by Chromatographic ANalyses

\begin{tabular}{lc} 
Nitrogen & $<0.05$ \\
Methane & 49.4 \\
Ethane & $<0.05$ \\
Carbon dioxide & $<0.05$ \\
Propane & 50.6 \\
Butane & $<0.05$ \\
\hline & $<100.2$
\end{tabular}

any runs are made and after every ten runs are complete. The first two sets of calibrations were consistent, and the twenty calibration points were fitted with an average deviation of $0.20 \%$.

The third set of calibration runs was found to differ by about $1 / 2 \%$ from the results of the first two. The flowmeter was removed from the system and ultrasonically cleaned. In addition, the entire section around the flowmeter was cleaned. The flowmeter was replaced and three sets of calibrations made. These gave reproducible results. The standard deviation of the

Table 2. Tabulated Values of Isobaric Heat Capacities for a Nominal 51 Mole \% Propane in Methane Mixture

Temperature, ${ }^{\circ} \mathrm{F}$

$$
C_{p} \text {, B.t.u. } /\left(\mathrm{lb}, \times{ }^{\circ} \mathrm{F} .\right)
$$
Pressure, lb./sq.in.abs.

$\begin{array}{ccccccc} & & & & & & \\ -280 & 0.546^{*} & 0.545 & 0.545 & 0.543 & 0.543 & 0.544 \\ -260 & 0.551^{*} & 0.549 & 0.550 & 0.546 & 0.546 & 0.548 \\ -240 & & 0.554 & 0.555 & 0.550 & 0.550 & 0.511 \\ -220 & & 0.560 & 0.560 & 0.555 & 0.555 & 0.556 \\ -200 & & 0.566 & 0.565 & 0.562 & 0.561 & 0.561 \\ -180 & & 0.572 & 0.571 & 0.568 & 0.567 & 0.566 \\ -160 & & 0.581 & 0.577 & 0.576 & 0.573 & 0.571 \\ -149.0 & & 0.586 & 0.581 & 0.580 & 0.577 & 0.574 \\ -140 & & 0.592 & 0.585 & 0.584 & 0.581 & 0.577 \\ -120 & & & 0.595 & 0.593 & 0.589 & 0.585 \\ -100 & & & 0.611 & 0.604 & 0.599 & 0.593 \\ -80 & & & & 0.618 & 0.611 & 0.602 \\ -60 & & & & 0.637 & 0.626 & 0.613 \\ -40 & & & & 0.661 & 0.643 & 0.627 \\ -20 & & & & 0.690 & 0.664 & 0.643 \\ 0 & & & & 0.730 & 0.692 & 0.662 \\ 3.5 & & & & 0.741 & 0.697 & 0.666 \\ 20 & & & & & 0.726 & 0.686 \\ 40 & & & & & 0.770 & 0.715 \\ 60 & 0.425 \dagger & & & & 0.833 & 0.749 \\ 80 & 0.435 \dagger & 0.508 & & & 0.907 & 0.787 \\ 100 & 0.446 \dagger & 0.510 & & & 0.979 & 0.821 \\ 110 & 0.451 \dagger & 0.511 & 0.664 & & 1.012 & 0.837 \\ 120 & 0.457 \dagger & 0.512 & 0.621 & & 1.031 & 0.852 \\ 130 & 0.462 \dagger & 0.514 & 0.605 & & 1.037 & 0.866 \\ 140 & 0.468 \uparrow & 0.516 & 0.596 & 1.009 & 1.030 & 0.879 \\ 150 & 0.473 \dagger & 0.518 & 0.589 & 0.904 & 1.009 & 0.889 \\ 151.2 & 0.475 \dagger & 0.518 & 0.588 & 0.877 & 1.003 & 0.891 \\ 160 & 0.479 \dagger & 0.520 & 0.583 & 0.837 & 0.980 & 0.895 \\ 170 & 0.485 \dagger & 0.523 & 0.580 & 0.790 & 0.948 & 0.891 \\ 180 & 0.490 \dagger & 0.525 & 0.577 & 0.756 & 0.916 & 0.882 \\ 190 & 0.496 \dagger & 0.529 & 0.575 & 0.730 & 0.885 & 0.873 \\ 200 & 0.502 \dagger & 0.532 & 0.575 & 0.710 & 0.857 & 0.862 \\ 210 & 0.507 \dagger & 0.536 & 0.575 & 0.695 & 0.831 & 0.850 \\ 220 & 0.513 \dagger & 0.540 & 0.576 & 0.684 & 0.808 & 0.837 \\ 230 & 0.519 \dagger & 0.545 & 0.578 & 0.675 & 0.788 & 0.825 \\ 240 & 0.524 \dagger & 0.549 & 0.579 & 0.669 & 0.771 & 0.814 \\ 251.3 & 0.531 \dagger & 0.555 & 0.582 & 0.663 & 0.754 & 0.803 \\ 260 & 0.536 \dagger & 0.560 & 0.585 & 0.661 & 0.743 & 0.795 \\ 280 & 0.547 \dagger & 0.570 & 0.592 & 0.656 & 0.726 & 0.780 \\ 300 & 0.558 \dagger & 0.579 & 0.600 & 0.655 & 0.718 & 0.767 \\ & & & & & & \end{array}$

- Experimental data of Cutler and Morrison (5). + Ideal gas values of Rossini et al. (32).
Table 3. Supplementary Table of Experimental Values of Isobaric Heat Capacity $C_{p}$ (B.t.u. $/$ L..$/{ }^{\circ}$ F.) Pressure

\begin{tabular}{|c|c|c|c|c|c|}
\hline \multicolumn{2}{|c|}{700 lb./sq.in.abs. } & \multicolumn{2}{|c|}{$\begin{array}{c}1,300 \\
\text { Ib./sq.in.abs. }\end{array}$} & \multicolumn{2}{|c|}{$\begin{array}{c}1,700 \\
\text { lb./sq.in.abs. }\end{array}$} \\
\hline Temp., ${ }^{\circ} \mathrm{F}$. & $C_{p}$ & $\begin{array}{l}\text { Temp., } \\
{ }^{\circ} \mathrm{F} \text {. }\end{array}$ & $C_{p}$ & $\begin{array}{l}\text { Temp., } \\
{ }^{\circ} \mathrm{F} \text {. }\end{array}$ & $C_{p}$ \\
\hline$-50(l)$ & 0.659 & 50 & 0.8623 & 110 & 0.9247 \\
\hline $135(\mathrm{~g})$ & 0.740 & 60 & 0.9013 & 120 & 0.9489 \\
\hline 140 & 0.724 & 70 & 0.9390 & 130 & 0.9581 \\
\hline 145 & 0.707 & 80 & 0.9889 & 140 & 0.9609 \\
\hline 150 & 0.692 & 90 & 1.0635 & 150 & 0.9602 \\
\hline 155 & 0.676 & 100 & 1.1320 & 160 & 0.9570 \\
\hline & & 110 & 1.1597 & 170 & 0.9532 \\
\hline & & 120 & 1.1486 & & \\
\hline & & 140 & 1.1171 & & \\
\hline & & 150 & 1.0208 & & \\
\hline & & 160 & 0.9678 & & \\
\hline & & 170 & 0.9141 & & \\
\hline
\end{tabular}

thirty-seven experimental calibration points from the correlating relation for these three sets is $0.16 \%$.

In obtaining data, inlet conditions of temperature and pressure are established, and flow rate and power input are adjusted to desired values. Readings are taken and adjustments made as necessary until the condition of steady state operation is obtained and maintained for at least $15 \mathrm{~min}$. A single determination generally lasts from 1 to $2 \mathrm{hr}$., depending on the magnitude of the changes made between determinations.

Isobaric measurements in the single-phase region are usually made in groups of four data points each. The inlet temperature is held constant, and adjustments in power input are made to yield temperature rises of approximately $10^{\circ}, 20^{\circ}, 40^{\circ}$, and $80^{\circ} \mathrm{F}$. In regions where $C_{p}$ varies significantly with temperature (such as in the critical region), smaller temperature rises were investigated. Isobaric determinations made through the twophase region also include determinations of the heat capacity of the liquid and vapor at temperatures respectively below and above the saturation temperatures.

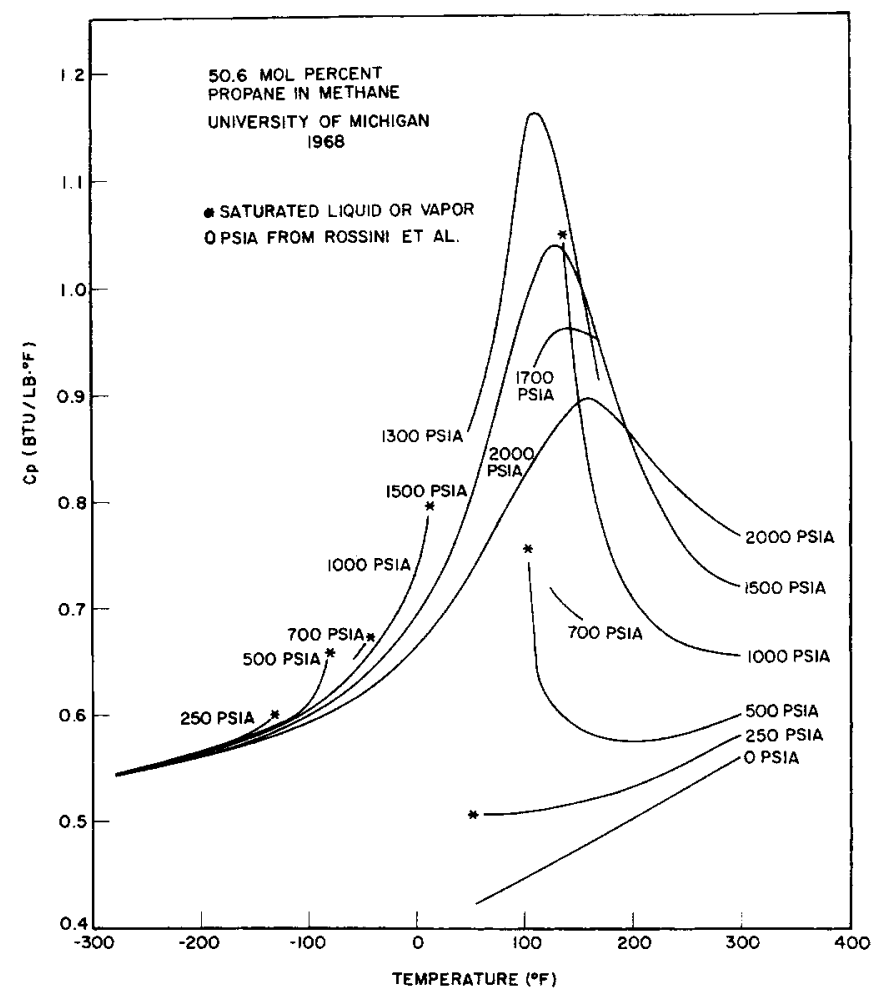

Fig. 4. Isobaric heat capacity of a mixture containing 50.6 mole $\%$ propane in methane. 

PressuRE, LB./SQ.IN.ABS.

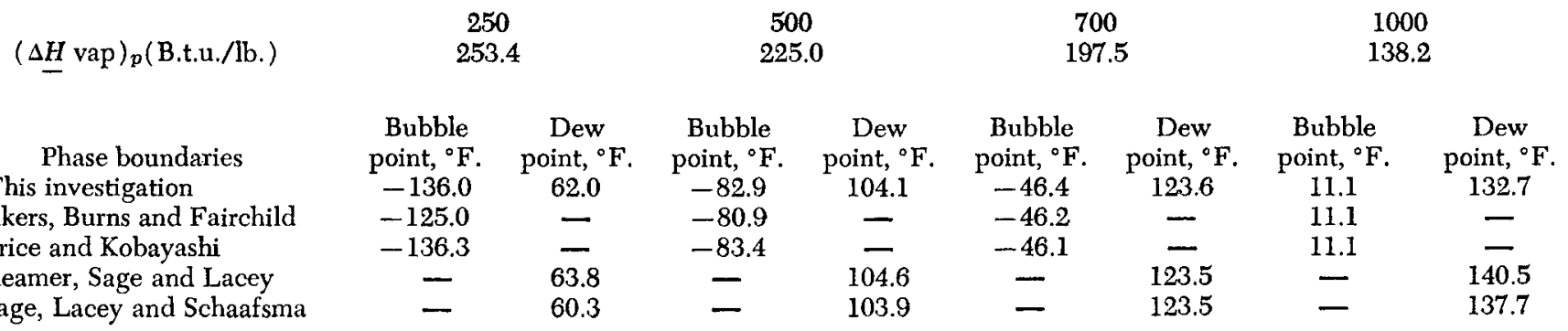

Isothermal determinations were made both in the singlephase region and into the two-phase region. The power input was adjusted until the outlet temperature was within $0.05^{\circ} \mathrm{F}$. of the inlet temperature. In general, pressure drops between 100 and $500 \mathrm{lb}$./sq.in. were used.

Isenthalpic determinations were made at conditions of constant inlet temperature. For a given inlet pressure, the flow rate was adjusted to yield a pressure drop of about 150 lb./sq.in. steady state conditions. The inlet pressure was then adjusted to a new value and the process repeated until the entire single-phase region was covered. For each operating condition, no electrical energy was transferred to the throttling calorimeter. The radiation shield was heated to the temperature of the exiting fluid to provide guard heating, thereby reducing to a negligible value the heat transfer by radiation and conduction through the vacuum jacket.

\section{Composition of Gas}

The methane used in this investigation was obtained from the Southern California Gas Company. The propane used was instrument grade as obtained from the Phillips Petroleum Company. Compositions of the mixture as determined by chromatographic analyses are reported in Table 1.

A chromatograph which is incorporated as part of the recycle flow facility was used for frequent checks on the composition of the gas in the system. The chromatograph was calibrated by using samples of known composition prepared by direct weighing.

From time to time the fluid composition did change. This was most frequent during periods of excessive leakage of fluid from the system. The composition was reestablished within reasonable limits by the addition of one component of the mixture and by remixing the entire system.

The chromatographic analyses on a day-to-day basis are summarized in Figure 2. There is no indication of a change in average composition with time.

\section{Check on Assumption of Adiabaticity}

In applying Equation (1) to interpret experimental data, it is assumed that the calorimeter is adiabatic. It has been established for the isobaric mode (27) that this condition is satisfied if the heat capacity determined by using the calorimcter is independent of the flow rate. Therefore, a series of isobaric determinations (run 18) was made at five different flow rates to test the assumption of zero heat leakage. A

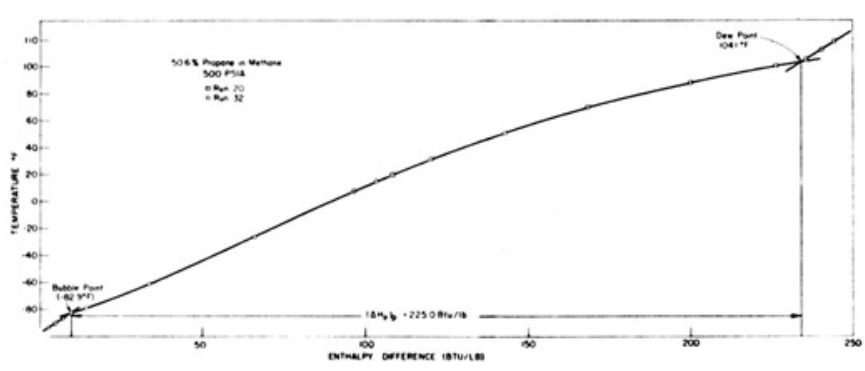

Fig. 5. Isobaric enthalpy troverse through the two-phase region at $500 \mathrm{lb} . / \mathrm{sq}$.in.abs. special effort was made to obtain data over a wide range of How rates $(0.055$ to $0.3 \mathrm{lb} \cdot \mathrm{m} / \mathrm{min})$. Within the limits of precision of the measurement $( \pm 0.3 \%)$ there was no influence of flow rate on heat capacity, and, therefore, it is concluded that the calorimeter is indeed adiabatic within these limits. These results are consistent with more extensive studies of this effect with the same calorimeter $(19,35)$.

\section{Results}

Experimental measurements of isobaric, isothermal, and isenthalpic changes in enthalpy for the mixture contained 50.6 mole $\%$ propane in methane have been presented in tabular form in Progress Reports to the Natural Gas Processors Association for the quarters ending March 31, 1968, and June 30,1968 . Included are determinations in both the gaseous and liquid regions, as well as isobaric and isothermal determinations within the two-phase regions. The ranges of pressures and temperatures covered by these experiments are indicated in part by the lines drawn on a PT diagram in Figure 9. In addition, isobaric determinations were made between $-250^{\circ}$ and $-150^{\circ} \mathrm{F}$. at $250,500,1,000,1,500$, and 2,000 lb./sq.in.abs.; between 100 and $200^{\circ} \mathrm{F}$. at $1,700 \mathrm{lb} . / \mathrm{sq} . \mathrm{in} . \mathrm{abs}$;

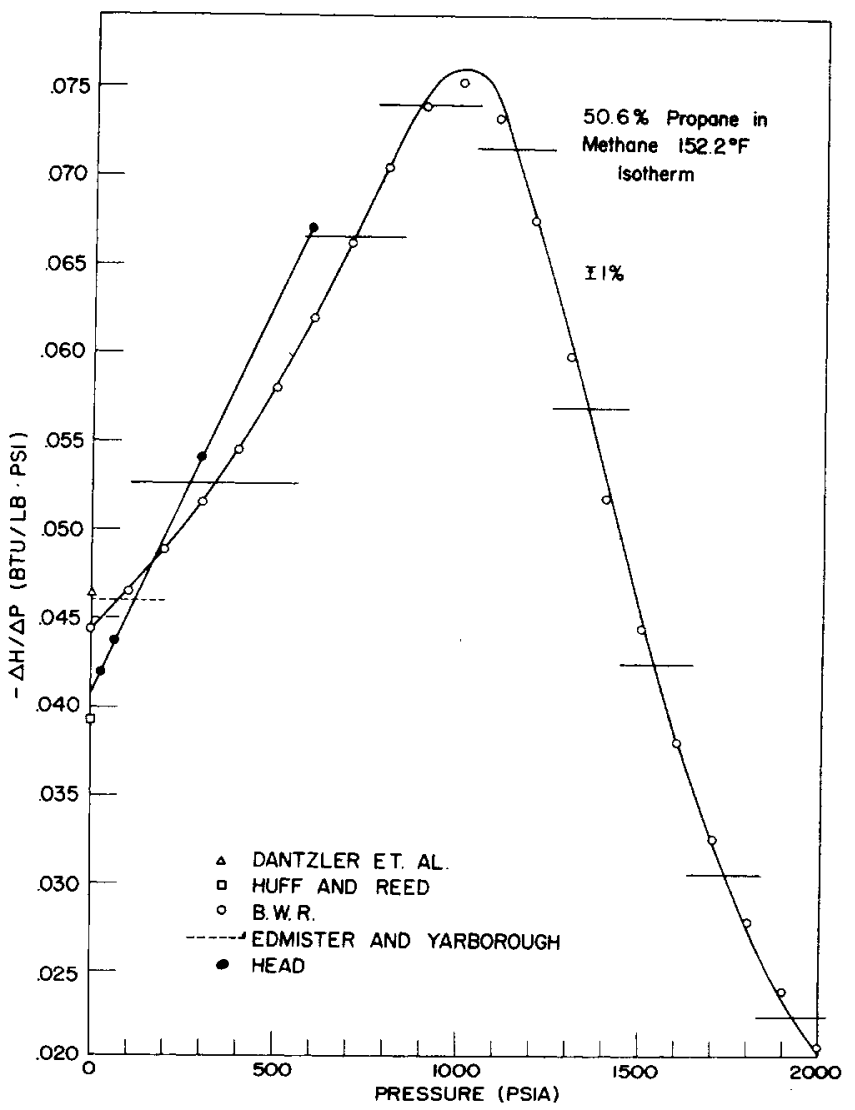

Fig. 6. Isothermal throttling coefficient at $152.2^{\circ} \mathrm{F}$. 
Table 5. Experimgntal Values of the Isothermal Throttling Coefficient $\phi$ ANd Joule-Thomson Coeffictent $\mu$ for a 51 Mole \% Propane in Methane Mixture

$-\mu \times 10^{3}$

lb./sq.in.abs.

${ }^{\circ} \mathrm{F} . /(\mathrm{lb} . / \mathrm{sq} . \mathrm{in} . \mathrm{abs}$. $-149.0$ Temperature, ${ }^{\circ} \mathrm{F}$.

$\phi \times 10^{2}$, B.t.u./(lb./sq.in.abs.)

$-149.0^{+}$

3.5

152.2

251.3

$-4.44$

$-3.30$

$-3.38$

$-4.90$

$+0.305$

$+0.306$

$-5.16$

$-3.46$

5.26

$+0.307$

$-5.46$

$+0.308$

$-5.81$

$-3.53$

5.30

$+0.309$

$-6.20$

$+0.310$

5.35

$+0.312$

5.40

$+0.313$

$+0.314$

$-0.1904$

$-6.62$

$-3.60$

$-3.67$

$-3.73$

$-3.79$

$-7.05$

$-7.45$

$-3.83$

$-3.85$

$-0.1463$

$-7.61$

$+0.315 \quad-0.1069$

$+0.317$

$-7.44$

$-3.83$

1,200

1,300

5.44

$+0.318$

$-0.0745$

$-0.0474$

$-0.0240$

$-0.0030$

$+0.321$

$+0.322$

$+0.324$

5.57

$+0.325$

5.62

$-6.80$

$-3.80$

$-3.75$

$-3.67$

$-5.31$

$-4.52$

$-3.82$

$+0.0156 t$

$+0.0320+$

$+0.0466 \mathrm{f}$

$+0.0593+$

- Extrapolated to 0 pressure based primarily on PVT data.

$\uparrow$ Calculated by using $\phi=-\mu C_{p}$.

between $50^{\circ}$ and $180^{\circ} \mathrm{F}$. at $1,300 \mathrm{lb} . / \mathrm{sq}$. in.abs.; and completely across the two-phase region at $700 \mathrm{lb} . / \mathrm{sq}$.in.abs.

\section{INTERPRETATION OF RESULTS}

\section{Isobaric}

Typical results are presented in Figure 3 on which mean values of heat capacity $(\Delta H / \Delta T)_{P}$ from experimental results are plotted vs. temperature. Solid lines indicate basic results obtained in accordance with the procedure described previously, and dashed lines are values obtained by differences from the basic results. A smoothed line is drawn through the data in keeping with integral requirements. Figure 3 illustrates the broad maximum in the heat

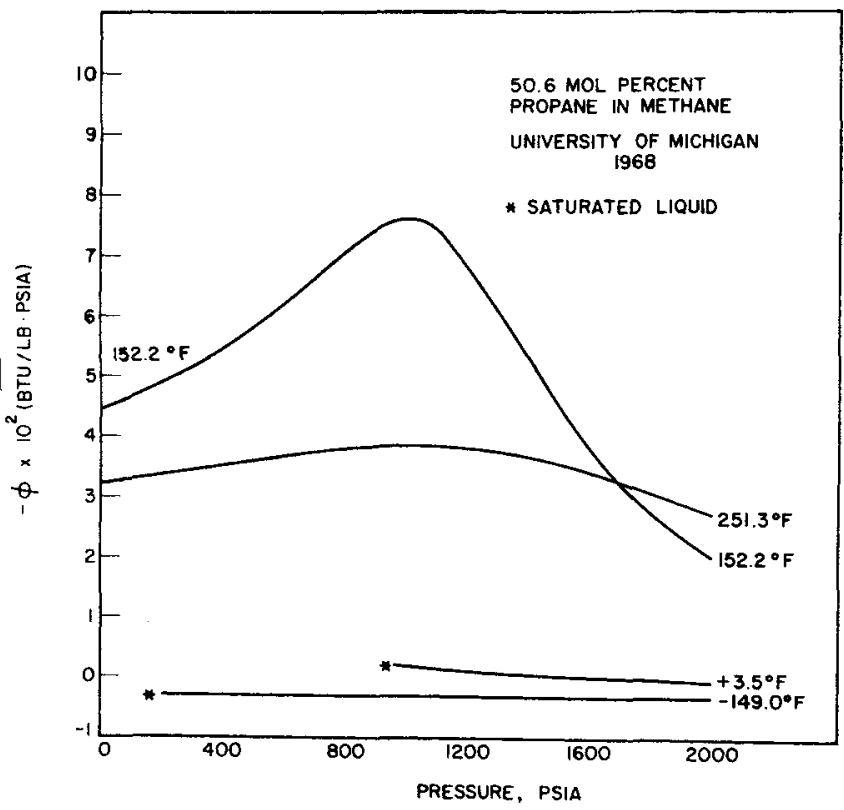

Fig. 7. Isothermal throttling coefficient for a mixture containing 50.6 mole \% propane in methane. capacity which occurs in the region just above the critical point for the mixture.

A majority of the values of heat capacity $C_{p}$, obtained from interpretation of isobaric data in the single-phase regions are summarized in Table 2 for equal intervals of temperature and pressure.

Significant changes in the value of the heat capacity occur not only in the region above the critical point for the mixture but also near the two-phase region. Table 3 lists values of heat capacity in the regions of significant change such as near the maxima in the heat capacity and near the saturation curves. All of the experimental heat capacity results are summarized in Figure 4.

A typical enthalpy traverse of the two-phase region at constant pressure is illustrated in Figure 5. Note that the traverse was made as two runs. This procedure was followed so that enthalpy traverses could be made across

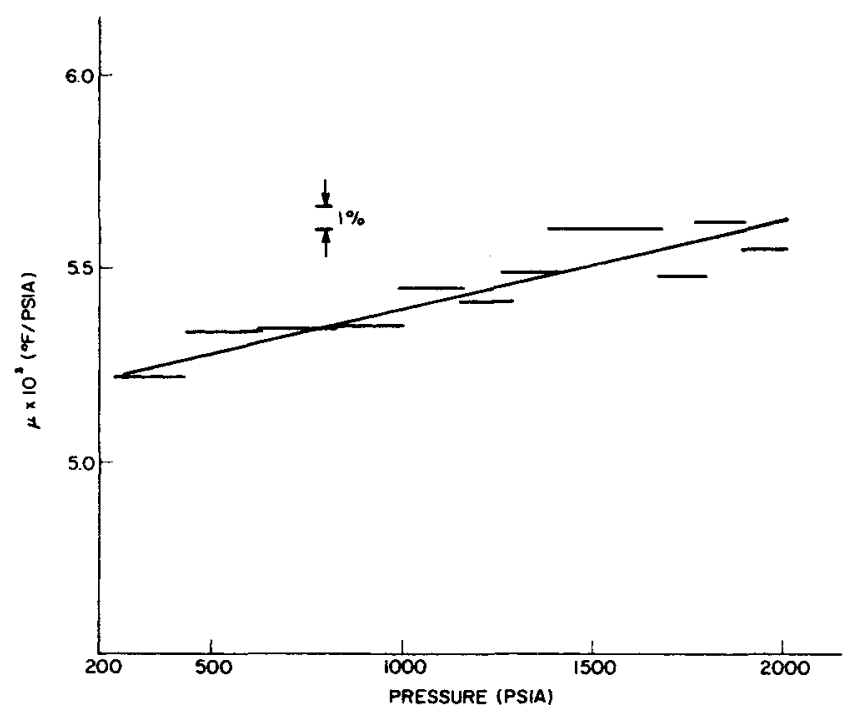

Fig. 8. Joule-Thomson coefficient at $-149.0^{\circ} \mathrm{F}$ 


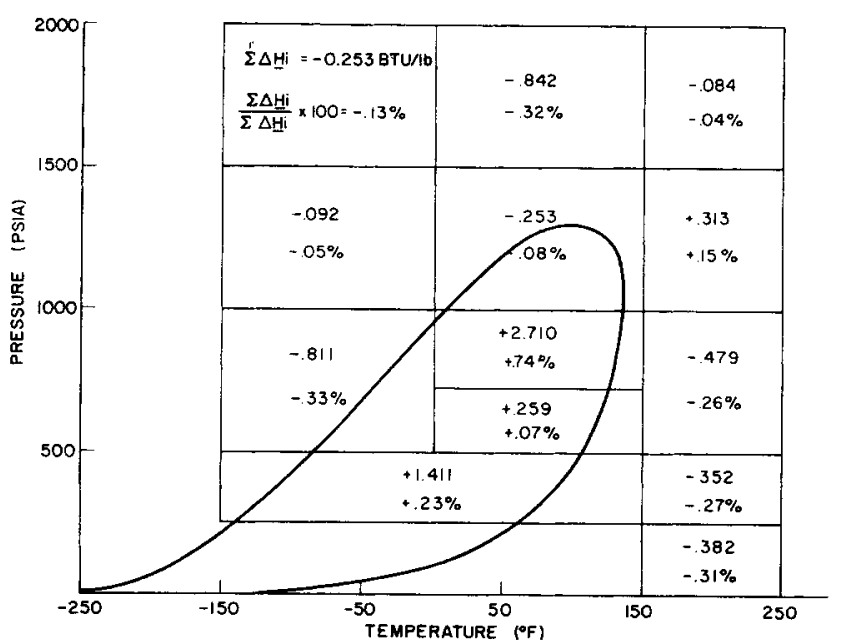

Fig. 9. Summary of self-consistency checks.

the two-phase regions at larger flow rates than would be possible if the entire change were experienced in one run. It has been found (36) that reliable results can be obtained when a two-phase mixture is fed to the calorimeter.

Determination of the points of discontinuity in slope of the curve yields values of the bubble point and dew point. Experimentally determined values of the isobaric enthalpy change on vaporization are listed in Table 4 together with the experimentally determined values of the bubble point and the dew point for the mixture.

\section{Isothermal}

The isothermal data obtained in the single-phase region were also interpreted in keeping with integral requirements by preparing plots of the average value of the isothermal throttling coefficient $(\Delta H / \Delta P)_{T}$ as a iunction of pressure. Typical results are shown in Figure 6. Note that a maximum exists in the curve, as the data were obtained at a temperature just above the two-phase region (see Figure 9).

As the lower limit on pressure in the facility is about $100 \mathrm{lb} . / \mathrm{sq}$.in.abs., it was necessary to estimate $\phi=f(P)$ at low pressures. To aid in this estimation, values were calculated from the BWR equation of state by using the original constants for methane and propane (2) together with mixing rules as originally suggested (3). Typical results are presented as open circles on Figure 6 . Note that the agreement between the BWR equation and the experimental values (indicated by horizontal bars) is ex-

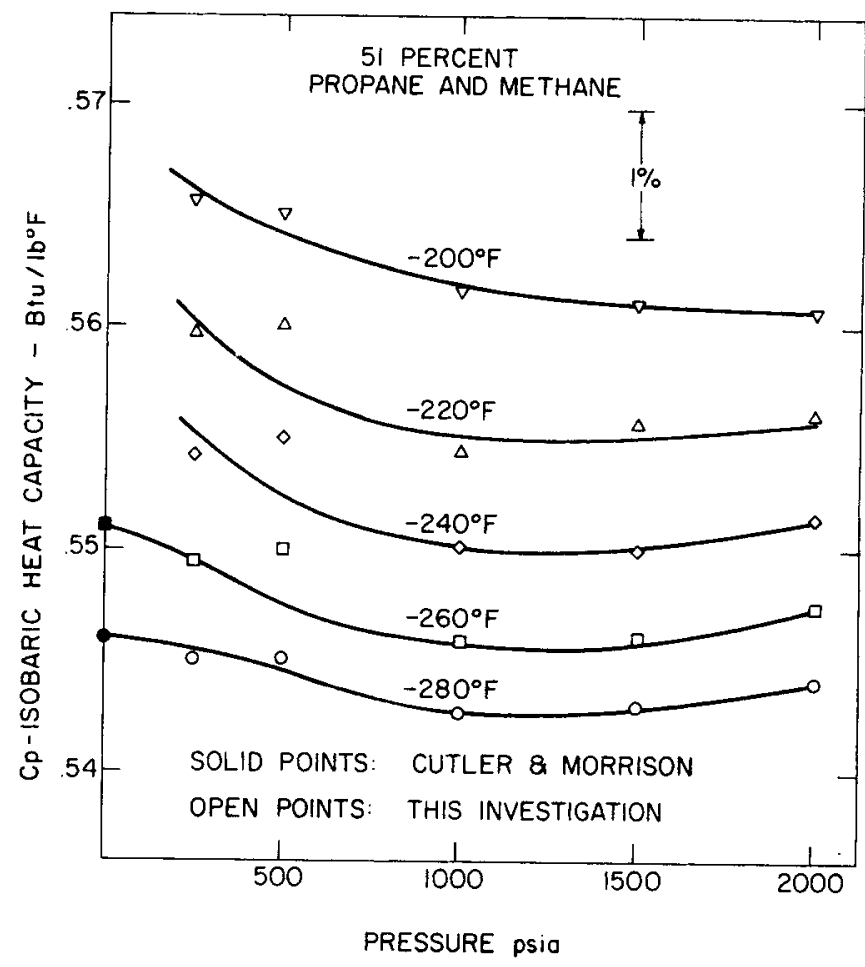

(b)

Fig. 10. The effect of pressure on $C_{p}$ at low temperatures including comparison with data of Cutler and Morrison (5).

ceptionally good throughout the entire region of pressure at this temperature.

In addition, PVT data for the mixture (29) as interpreted (7) by using Equation (5) yielded values of $\left[\left(\underline{H}^{\circ}-H\right) / \Delta P\right]_{T}$ between 0 pressure and 200 lb./sq.in-abs. A typical value is presented as a dashed line on Figure 6. In addition, Equations (2) to (4) were used with published values of the second virial coefficient for methane and propane and the interaction term $(6,12)$ to estimate $\phi \mathrm{deg}$. The resulting values at $152.5^{\circ} \mathrm{F}$, are plotted on Figure 6 . Values from the two sources $(6,12)$ disagree by over $15 \%$. Finally, values of $\mu$, the JouleThomson coefficient, have been measured by Head (vv) for a 51.1 mole \% propane in methane mixture at low pressures. Experimentally measured heat capacities and Joule-Thomson coefficient data are combined according to $\phi=-\mu C_{p}$ and are presented as solid circles on Figure 6.

Table 6. Tabulated Values of Enthalpy of Saturated Mixtures Containing 51 Mole \% Propane in Methane

Pressure,

lb./sq.in.abs.

$\begin{array}{rr}100 & -180 \\ 200 & -149 \\ 300 & -125 \\ 400 & -103 \\ 500 & -83 \\ 600 & -66 \\ 700 & -46 \\ 800 & -27 \\ 900 & -9 \\ 1,000 & 11 \\ 1,100 & 31 \\ 1,200 & 51 \\ 1,300 & 79\end{array}$

Temperature, ${ }^{\circ} \mathrm{F}$. Bubble point Dew point

13
50
73
91
104
116
124
132
137
137
136
131
114

Saturated liquid enthalpy B.t.u./lb.

56.6
74.8
89.7
102.9
115.4
127.8
140.0
152.7
165.8
180.0
194.5
210.2
235.4

Saturated vapor enthalpy, B.t.u./lb.
Latent heat of vaporization, B.t.u./lb.

$\begin{array}{lr}327.0 & 270.4 \\ 335.5 & 260.7 \\ 339.6 & 249.9 \\ 341.3 & 238.4 \\ 341.5 & 226.1 \\ 340.6 & 212.8 \\ 338.4 & 198.4 \\ 335.6 & 182.9 \\ 330.4 & 164.6 \\ 322.2 & 142.2 \\ 312.1 & 117.6 \\ 299.6 & 89.4 \\ 276.5 & 41.1\end{array}$


Temper-

ature, ${ }^{\circ} \mathrm{F}$.

\begin{tabular}{cc}
-280 & 234.0 \\
-260 & 240.2 \\
-240 & 246.5 \\
-220 & 252.9 \\
-200 & 259.3 \\
-180 & 265.8 \\
-160 & 272.4 \\
-149.0 & 276.0 \\
-140 & 279.1 \\
-120 & 285.9 \\
-100 & 292.9 \\
-80 & 300.0 \\
-60 & 307.2 \\
-40 & 314.7 \\
-20 & 322.3 \\
0 & 330.1 \\
3.5 & 331.4 \\
20 & 338.0 \\
40 & 346.2 \\
60 & 354.6 \\
80 & 363.2 \\
100 & 372.0 \\
120 & 381.0 \\
140 & 390.3 \\
152.2 & 396.0 \\
160 & 399.8 \\
180 & 409.5 \\
200 & 419.4 \\
220 & 429.5 \\
240 & 439.9 \\
251.3 & 445.8 \\
260 & 450.5 \\
280 & 461.3 \\
300 & 472.3 \\
0 & \\
\hline &
\end{tabular}

- Indicates values within the two-phase region.
H, B.t.u./lb.

\begin{tabular}{|c|c|c|c|c|c|}
\hline \multicolumn{3}{|c|}{ Pressure, lb./sq.in.abs. } & \multirow[b]{2}{*}{1,500} & \multirow[b]{2}{*}{1,750} & \multirow[b]{2}{*}{2,000} \\
\hline 750 & 1,000 & 1,250 & & & \\
\hline 2.9 & 3.9 & 4.9 & 6.0 & 6.7 & 7.5 \\
\hline 13.9 & 15.1 & 16.0 & 16.7 & 17.6 & 18.5 \\
\hline 24.9 & 26.0 & 26.8 & 27.7 & 28.5 & 29.5 \\
\hline 36.3 & 37.0 & 37.6 & 38.7 & 39.6 & 40.4 \\
\hline 47.4 & 48.2 & 49.0 & 49.9 & 50.7 & 51.7 \\
\hline 58.8 & 59.6 & 60.4 & 61.3 & 62.1 & 62.8 \\
\hline 70.2 & 71.0 & 71.7 & 72.5 & 73.3 & 74.4 \\
\hline 76.5 & 77.2 & 78.0 & 78.9 & 79.7 & 80.5 \\
\hline 81.4 & 82.6 & 83.5 & 84.3 & 85.0 & 85.8 \\
\hline 93.6 & 94.3 & 95.0 & 95.8 & 96.5 & 97.4 \\
\hline 105.5 & 106.2 & 107.0 & 107.6 & 108.3 & 109.2 \\
\hline 118.1 & 118.5 & 118.9 & 119.6 & 120.3 & 121.2 \\
\hline 131.3 & 131.0 & 131.3 & 132.0 & 132.5 & 133.3 \\
\hline $143.9^{*}$ & 143.9 & 144.2 & 144.7 & 145.2 & 145.7 \\
\hline $163.4^{*}$ & 157.5 & 157.6 & 157.9 & 158.0 & I58.4 \\
\hline $182.1^{*}$ & 171.5 & 171.3 & 171.3 & 171.2 & 171.6 \\
\hline $185.1^{\circ}$ & 174.1 & 173.9 & 173.7 & 173.6 & 173.8 \\
\hline $200.8^{*}$ & 188.3 & 185.6 & 185.2 & 185.0 & 185.0 \\
\hline $220.2^{*}$ & $208.1^{\circ}$ & 201.1 & 200.1 & 199.3 & 199.0 \\
\hline $239.8^{*}$ & $227.6^{*}$ & 218.3 & 216.3 & 214.6 & 213.7 \\
\hline $63.0^{\circ}$ & $248.4^{\circ}$ & $238.4^{\circ}$ & 233.8 & 231.0 & 229.1 \\
\hline $290.2^{*}$ & $271.7^{\star}$ & $259.9^{*}$ & 252.2 & 247.8 & 245.1 \\
\hline $323.8^{\circ}$ & $298.7^{*}$ & $283.4^{\circ}$ & 272.5 & 266.0 & 262.0 \\
\hline 346.1 & 325.8 & 306.7 & 293.1 & 284.7 & 279.5 \\
\hline 355.0 & 337.2 & 319.2 & 305.5 & 296.1 & 290.1 \\
\hline 360.8 & 344.1 & 327.1 & 313.2 & 303.6 & 297.1 \\
\hline 374.2 & 359.8 & 345.0 & 332.0 & 322.5 & 314.9 \\
\hline 387.1 & 374.5 & 361.7 & 350.1 & 340.6 & 332.5 \\
\hline 399.9 & 388.7 & 377.3 & 366.5 & 357.3 & 349.5 \\
\hline 412.4 & 402.3 & 392.1 & 382.2 & 373.7 & 366.0 \\
\hline 419.2 & 409.6 & 399.9 & 390.8 & 382.5 & 375.0 \\
\hline 424.9 & 415.4 & 407.2 & 397.4 & 389.3 & 382.1 \\
\hline 437.3 & 428.5 & 420.1 & 411.9 & 404.6 & 397.7 \\
\hline 449.7 & 441.8 & 434.1 & 426.5 & 419.7 & 413.2 \\
\hline
\end{tabular}

There is considerable disagreement between the results of the various methods. The solid line on Figure 6 was drawn to be consistent with the data obtained at elevated pressures and the estimates based on data from the literature in the low pressure range. In the low pressure region the line was drawn to agree with the BWR equation of state because of its excellent agreement with the high pressure data. This line was also reasonably consistent with volumetric data. Values of the isothermal throttling coefficient $\phi$ obtained by interpreting the data (including values of $\phi$ deg. and other values at low pressure determined as outlined above) are reported for each of the experimental isotherms in Table 5. These data are summarized in Figure 7.

One experimental isothermal run was made into the twophase region at $3.5^{\circ} \mathrm{F}$. A break in the curve was obtained at $966 \mathrm{lb} . / \mathrm{sq}$. in.abs. This break indicated the upper pressure at which vaporization starts.

\section{Isenthalpic}

Twelve determinations were made with the throttling calorimeter under conditions such that a drop in pressure resulted in an increase in temperature. The inlet temperature was constant at $-149.0^{\circ} \mathrm{F}$. in all cases. The scatter in the data of greater than $1 \%$ as illustrated in Figure 8 is the result of the measurement of unusually small temperature differences due to the small Joule-Thomson effect at these conditions. When this effect is related to an enthalpy difference and used in the preparation of a table of enthalpy values, the error involved in this scatter becomes extremely insignificant. The values of the Joule-Thomson coefficient determined from these data are summarized in Table 5 .

\section{Consistency Checks}

If isobaric, isothermal, and isenthalpic data are obtained for a system at properly selected values of pressure and temperature, it is possible to check the thermodynamic consistency of such data. The principle of this check has been illustrated previously (36). Experimentally determined isobars and isotherms intersect forming closed loops which are shown in Figure 9 . The sum of the enthalpy differences about such loops should be zero. A measure of the consistency of such data can be expresses as a percentage deviation for a loop defined as

$$
\begin{aligned}
& \text { Percentage } \\
& \text { deviation }
\end{aligned}=\frac{\sum_{i}\left|\Delta \underline{H}_{i}\right|}{\sum_{i} \Delta H_{i}} \times 100
$$

Figure 9 shows the results of all of the consistency checks made with the data obtained for this system. Values are presented only for the smallest loops, as bigger loops will usually yield a value for percentage deviation that is smaller than the largest included within the con- 
stituent smaller loops. As can be seen, the largest percentage deviation is $0.74 \%$ for a loop which included both isobaric and isothermal data within the two-phase region. For other systems which have been investigated with the present recycle facility, the maximum error has been consistently less than $0.5 \%(19,35,37)$. Thus, the $0.74 \%$ maximum deviation is considered to be larger than normal. The average absolute deviation for the thirteen loops was found to be $0.23 \%$. This should give a better indication of the accuracy of the data presented.

\section{ENTHALPY DIAGRAM}

The data reported in previous sections have been used to prepare a skeleton table of values of the enthalpy of this mixture at selected values of pressure and temperature as reported in Tables 6 and 7.

The following procedure was used in preparing the skeleton table and the diagram:

1. Reference states were taken to be $H=0$ B.t.u. $/$ lb. for both of the pure components as saturated liquids at $-280^{\circ} \mathrm{F}$. This choice is consistent with that previously used for pure methane (14), pure propane (38), and for other mixtures of propane and methane which have been investigated $(16,17,19,25,20,35)$.

2. Data from the literature and the BWR equation of state with the original constants (2) were utilized to determine the enthalpy of pure methane and pure propane at $152.2^{\circ} \mathrm{F}$, as summarized below:

$$
\begin{aligned}
& \text { Methane } \\
& \text { Enthalpy change on vaporization at } \\
& -280^{\circ} \mathrm{F} .(10) \\
& \text { Effect of pressure on enthalpy from } 5 \\
& \text { to } 0 \text { (BWR) } \\
& \Delta \underline{H} \text { (B.t.u./lb.) } \\
& +228.27 \\
& +\quad 1.43
\end{aligned}
$$

3. The enthalpy of the propane-methane mixture at 0 pressure and $152.2^{\circ} \mathrm{F}$. was calculated by assuming negligible heat of mixing under these conditions. The molecular weight of methane was taken to be 16.042 and that of propane 44.094. The resulting value for the mixture is $396.05 \mathrm{Btu} / \mathrm{lb}$.

4. The isothermal effect of pressure on the enthalpy of the mixture at $152.2^{\circ} \mathrm{F}$. was established from the basic experimental data obtained at this temperature (see Figure 6). As indicated previously, extrapolation of the experimental data to 0 pressure was necessary and in-

- This value provides a basis for changing to other reference states. For example, using the tabulated value of API 44 with a reference state of $H=0$ at $0^{\circ} \mathrm{K}$. and 0 pressure for the ideal gas, one interpolates to obtain a value of 210.5 B.t.u./lb. Thus one should subtract 185.5 B.t.u./ lb. from all values presented in this contribution to convert to the API 44 reference states.

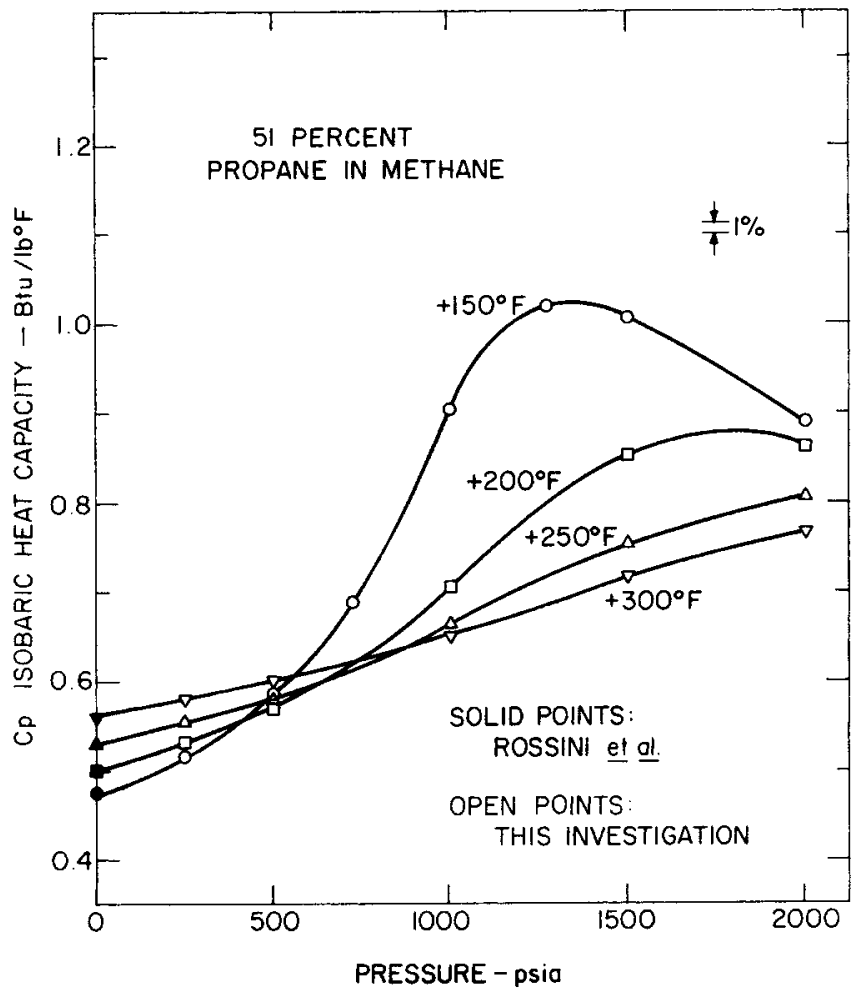

(b)

Fig. 11. The effect of pressure on $C_{p}$ at high temperatures including comparison with published values of Rossini et al. (32).

volved application of data from the literature $(2,3,6,7$, $12,29)$.

5. Isobaric data reported in this manuscript were used at various pressures to determine the isobaric effect of temperature on enthalpy at elevated pressures in both the gaseous and liquid regions as well as within the two-phase envelope. The limits of the two-phase region were determined by using results from the traverses of the two-phase region which were made during the course of this investigation (Table 4 and Figure 5) supplemented by data from the literature $(1,28,29,31,33,34)$.

6. A skeleton table of values determined in this manner was prepared. Slight adjustments were made in the values such that all deviations reported in Figure 9 were reduced to 0 . The final results are presented as Tables 6 and $7 .{ }^{\circ}$

\section{COMPARISON WITH OTHER PUBLISHED DATA}

\section{Enthalpy Dota}

There are some data in the literature which permit direct comparison with the data reported here. Cutler and Morrison (5) report data on the heat capacity of liquid mixtures of methane and propane at temperatures around $-280^{\circ} \mathrm{F}$. as well as data on the heat of mixing of liquid methane and propane at $-280^{\circ} \mathrm{F}$. Values of the heat capacity at $-260^{\circ}$ and $-280^{\circ} \mathrm{F}$. for the saturated liquid based on data reported by Cutler and Morrison are plotted on Figure 10 together with values obtained by extrapolation to lower temperatures of isobaric determinations at elevated pressures. The data from these independent investigations are consistent and illustrate the effect of pressure on the isobaric heat capacity in the dense fluid region.

Values of the heat capacity of the mixture can be

These results are available in the form of two $11 \times 17$ in. graphs for $\$ 1.00$ per set from J. E. Powers. 
calculated at 0 pressure from published values of ideal heat capacities (32). Values thus determined are plotted on Figure 11 together with values obtained during the course of this investigation. These values from independent sources are consistent and illustrate the effect of pressure on the isobaric heat capacity in the gaseous region at temperatures just above the two-phase envelope.

Data on the Joule-Thomson coefficient $\mu$ have been published for a 51.1 mole \% propane in methane mixture at $152^{\circ} \mathrm{F}$. at pressures up to $600 \mathrm{lb}$./sq.in.abs. by Head (11). As indicated on Figure 6, the results of Head disagree with values obtained during this investigation by as much as $10 \%$. Other Joule-Thomson coefficient data have been published for several binary mixtures of methane and propane over a wide temperature range and up to $1,500 \mathrm{lb}$./sq.in.abs. (4). These latter values were interpolated with respect to composition to establish values at 50.6 mole \% propane. These results were in good agreement with the results of $\mathrm{Head}$ but disagreed by as much as $12 \%$ with values of $\mu=-\phi / C_{p}$ calculated by using data reported in this contribution.

\section{Phase Behavior}

A number of independent investigators have reported data on the vapor-liquid equilibrium of the methanepropane system $(1,28,29,34)$. Data from these sources were used to estimate bubble and dew points corresponding to the pressures of investigation reported in Table 6 . These results are included in Table 6 and indicate not only the variation among the various investigators, but give some indication of the accuracy of the vapor-liquid equilibrium measurements made in the course of the present investigation.

\section{ACKNOWLEDGMENT}

The authors thank A. W. Furtado, J. C. Golba, and J. F. Boissonneault for their substantial part in obtaining the experimental data. This research was financed primarily with funds administered by the Thermodynamics Advisory Committee of the Natural Gas Processors Association. J. C. Golba was supported by a grant from the American Petroleum Institute. The National Bureau of Standards provided a number of essential calibrations.

\section{NOTATION}

$B=$ second virial coefficient

$B_{11}, B_{22}=$ second virial coefficient for pure components 1 and 2

$B_{12}=$ second virial interaction parameter for a mixture of components 1 and 2

$C_{p}=$ heat capacity of constant pressure

$F=$ mass flow rate

$\underline{H}=$ specific enthalpy

$\bar{P} \quad=$ pressure

$\dot{Q}=$ rate of heat transfer

$T=$ temperature

$\underline{V}=$ specific volume

$\bar{x}=$ mole fraction

$\dot{W}=$ rate of electrical energy transfer

$\Delta H_{i}=$ enthalpy difference of one part of a loop with sign corresponding to a clockwise path around the loop

$\mu \quad=$ Joule-Thomson coefficient

$\phi \quad=$ isothermal throttling coefficient

\section{LITERATURE CITED}

1. Akers, W. W., J. F. Burns, and W. R. Fairchild, Ind. Eng. Chem., 46, 2531 (1954).
2. Benedict, M., G. B. Webb, and L. C. Rubin, J. Chem. Phys., 8, 334(1940).

3. Ibid., 10,747 (1942).

4. Budenholzer, R. A., D. F. Botkin, B. H. Sage, and W. N. Lacey, Ind. Eng. Chem., 32, 878 (1942).

5. Cutler, A. J. B., and J. A. Morrison, Trans. Faraday Soc., 61, 429 (1965).

6. Dantzler, E. M., C. M. Knobler, and M. L. Windsor, J. Phys. Chem., 72, 676 (1968).

7. Edmister, W. C., and Lyman Yarborough, AIChE J., 9, 240 (1963)

8. Ernst, G., Ph.D. dissertation, Universität Karlsruhe, Germany (1967).

9. Faulkner, R. C., Jr., Ph.D. thesis, Univ. Mich., Ann Arbor (1959).

10. Frank, A., and K. Clusius, Z. physik. Chem., B36, 291 (1937).

11. Head, J. F., Ph.D. thesis, Univ. London, England (1960).

12. Huff, J. A., and T. M. Reed, III, J. Chem. Eng. Data, 8, 306 (1963).

13. Jones, M. L., Jr., Ph.D. thesis, Univ. Mich., Ann Arbor (1961).

14. Jones, M. L., Jr., D. T. Mage, R. C. Faulkner, Jr., and D. L. Katz, Chem. Eng. Progr. Symposium Ser. No. 44, $59,52(1963)$.

15. Kemp, J. D., and C. J. Egan, J. Am. Chem. Soc., 60, 1521 (1938).

16. Manker, E. A., Ph.D. thesis, Univ. Mich., Ann Arbor (1964).

17. Manker, E. A., D. T. Mage, A. E. Mather, J. E. Powers, and D. L. Katz, Proc. Ann. Conv., Natl. Gas Process. Assoc., Tech. Papers, 43, 3 (1964).

18. Manker, E. A., A. E. Mather, V. L. Bhirud, D. L. Katz, and J. E. Powers, forthcoming publication.

19. Mather, A. E., Ph.D. thesis, Univ. Mich., Ann Arbor (1967).

20. $\longrightarrow$ D. L. Katz, and J. E. Powers, Trans. Faraday Soc., 64, 2939 (1968).

21. , Proc. Ann. Conv., Natl. Gas Process. Assoc., Tech. Papers, 44, 3 (1965).

22. Schäfer, ed., pp. I, 6, 1, Heidelberg, Germany (Sept., 1967).

23. —, AIChE J., 15, No. 1 (Jan., 1969).

24. Mather, A. E., V. F. Yesavage, D. L. Katz, and J. E. Powers, Proc. Ann. Conv. Natl. Gas Process. Assoc., Tech. Papers, 46, 8 ( 1967).

25. Ibid., 45, 12 (1966)

26. Ibid., 46, 3 (1967).

27. Montgomery, J. B., and T. DeVries, J. Am. Chem. Soc., 64, 2372 ( 1942 ).

28. Price, A. R., and Riki Kobayashi, J. Chem. Eng. Data, 4, 40 (1959).

29. Reamer, H. H., B. H. Sage, and W. N. Lacey, Ind. Eng. Chem., 42, 534 (1950). See corrections, Ind. Eng. Chem., 42,1258 (1950).

30. Roebuck, J. R., Phys. Rev., 2, 299 (1913).

31. Roof, J. G., and J. D. Baron, J. Chem. Eng. Data, 12, 292 (1967).

32. Rossini, F. D., et al., "Selected Values of Physical and Thermodynamic Properties of Hydrocarbons and Related Compounds," Carnegie Press, Pittsburgh, Pa. (1953).

33. Rutherford, W. M., Soc. Petrol. Engrs. J., 2, 340 (1962).

34. Sage, B. H., W. N. Lacey, and J. G. Schaafsma, Ind. Eng. Chem., 26, 214 (1934).

35. Yesavage V. F., Ph.D. thesis, Univ. Mich., Ann Arbor (1968).

36. — , A. W. Furtado, and J. E. Powers, Proc. Ann. Conv. Natl. Gas Process. Assoc., Tech. Papers, 47, 3 (1968).

37. Yesavage, V. F., D. L. Katz, and J. E. Powers, "Fourth Symposium on Thermophysical Properties," Am. Soc. Mech. Engrs., New York (1968).

38. ical Society Meeting, Atlantic City, N. J. (Sept. 8-13, 1968).

Manuscript received October 8, 1968; revision received February 3, 1969; paper accepted February 5, 1969. Paper presented at AIChE New Orleans meeting. 